\title{
Carotenoid content and antioxidant activity of fourteen tomato ketchups available in the UK
}

\author{
J. E. Brown ${ }^{1}$, E. Cropp ${ }^{1}$ and V. Rizzo ${ }^{2}$ \\ ${ }^{1}$ Division of Nutritional Sciences, Faculty of Health and Medical Sciences, University of Surrey, Guildford GU2 7XH, \\ Surrey, UK and ${ }^{2}$ Sezione Tecnologie Agroalimentari, Dipartimento di Orto-Floro-Arboricoltura e Tecnologie \\ Agroalimentari (DOFATA), University of Catania, Via S Sofia, 98 - 95123 Catania, Italy
}

Carotenoids are a class of phytonutrient present in a variety of fruits and vegetables. Tomatoes (and their products) can be a particularly good source of carotenoids (especially lycopene) and their consumption is correlated with a reduced risk of some cancers (e.g. prostate cancer $\left.{ }^{(1)}\right)$ and $\mathrm{CVD}^{(2)}$. Several factors have resulted in an increase in tomato ketchup consumption in the Western world ${ }^{(3)}$ that may be viewed as detrimental, but may also be beneficial to health. At present there is little information on the carotenoid content of ketchups available in the UK.

Lycopene and $\beta$-carotene were extracted from fourteen different ketchups (diluted 1 in 10 with distilled water) using dichloromethane then analysed by HPLC with detection at 480 and $460 \mathrm{~nm}$ respectively after separation on a $\mathrm{C}_{30}$ column ${ }^{(4)}$. Antioxidant activity (AA) was assessed on the lipophilic extracts spectrophotometrically using the Trolox equivalent antioxidant capacity assay ${ }^{(5)}$.

\begin{tabular}{lcccccccccccccccc}
\hline Ketchup. . & SL1 & SL2 & SL3 & SR1 & SR2 & SR3 & SR4 & SR5 & SP1 & M1 & M2 & M3 & M4 & O1 \\
\hline Lycopene* & 60 & 128 & 179 & 160 & 176 & 189 & 192 & 213 & 242 & 78 & 139 & 186 & 212 & 192 \\
B-carotene* & 4.6 & 2.4 & 5.0 & 7.9 & 5.9 & 4.1 & 5.6 & 4.6 & 8.2 & 3.2 & 4.8 & 3.5 & 8.3 & 5.5 \\
Tomato content $\dagger$ & 103 & 97 & 115 & 156 & 181 & 172 & 172 & 140 & 103 & 106 & 126 & 153 & ND & ND \\
AA $\neq$ & 0.45 & 0.47 & 0.73 & 0.67 & 0.79 & 0.61 & 0.75 & 0.74 & 1.04 & 0.41 & 0.72 & 0.68 & 1.03 & 0.93 \\
\hline
\end{tabular}

SL, supermarket low-price product; SR, supermarket regular-price product; SP, supermarket premium-price product; M, manufacturer's product; O, organic product; ND, no data available. ${ }^{*}$ Values $(\mu \mathrm{g} / \mathrm{g})$ are means for four determinations. $\dagger \mathrm{g} / 100 \mathrm{~g}$ finished product. $\$$ Values (mmol Trolox equivalents/l) are means for three determinations.

A 4-fold variation in lycopene content was observed, with the highest level measured in a supermarket premium product (SP1) and the lowest level measured in a supermarket low-price product (SL1). For $\beta$-carotene a manufacturer's own brand contained the highest level with the lowest level observed for a supermarket low-price product (SL2). For AA the SP1 ketchup contained the highest activity whereas a manufacturer's own brand ketchup (M1) possessed the lowest. Both lycopene and $\beta$-carotene content correlated with AA $(r$ 0.845 and 0.769 respectively, $P<0.001)$ ). Significant correlations were also observed between tomato content and carotenoid concentrations $(r 0.749$ and 0.608 for lycopene and $\beta$-carotene respectively). These results are consistent with data from other studies ${ }^{(3,6)}$ and taken together with information on ketchup intake indicate that ketchup consumption could contribute to between 8 and $38 \%$ of UK lycopene intake.

1. Miller EC, Giovannucci E, Erdman JW et al. (2002) Urol Clin North Am 29, 83-93.

2. Rissanen TH, Voutilainen S, Nyyssonen K et al. (2001) Br J Nutr 85, 749-754.

3. Ishida BK \& Chapman MH (2004) J Agric Food Chem 52, 8017-8020

4. Muratore G, Rizzo V, Licciardello F et al. (2008) Food Chem 111, 887-891

5. Re R, Pellegrini N, Proteggente A et al. (1999) Free Radic Biol Med 26, 1231-1237

6. Markovic K, Hruskar M \& Vahcic N (2006) Nutrition Research 26, 556-560 